\title{
Ontogenetic Habitat Shifts of Juvenile Bear Lake Sculpin
}

\author{
James R. RuZyCKI*1 and Wayne A. Wurtsbaugh \\ Department of Fisheries and Wildlife and Ecology Center, \\ Utah State University, Logan, Utah 84322-5210, USA
}

\begin{abstract}
Bear lake sculpin Cottus extensus exhibit ontogenetic habitat shifts during their initial year of life. Distribution and habitat switching was measured with bimonthly bottom-trawl surveys repeated throughout the summer. Patterns of daily growth increments on otoliths were used to measure the history of habitat residence, individual size at the time of the habitat switch, and habitat-specific growth rates. Laboratory experiments and known-age fish confirmed daily increment formation of otoliths. After dispersing during an initial pelagic larval stage, postlarval juveniles settled in both the warm, food-rich littoral zone and the cold, unproductive profundal zone. During summer, initial profundal-zone inhabitants underwent a unidirectional habitat shift to the more productive littoral zone. Fish that moved to the littoral zone grew twice as fast as those in the profundal zone and encountered little apparent predation mortality risk there. Habitat shifts were therefore consistent with both growth optimization and predatory avoidance. However, shifts occurred at a wide range of body sizes throughout the summer. The large spatial scale of the lake, limited swimming ability of juvenile fish, diel migratory behavior, and lack of complex habitat structure may preclude shifts at discrete body sizes for this species.
\end{abstract}

Ontogenetic shifts in resource use are nearly universal for lacustrine fishes (Werner and Gilliam 1984). For several freshwater fish species, small changes in body size have been demonstrated to influence habitat use during the initial year of growth (e.g., Mittelbach 1981; Rice et al. 1987; Post and McQueen 1988; Luecke et al. 1990). Growth rate may also affect how long an individual is susceptible to a size-related predation risk (Crowder et al. 1987; Post and Prankevicius 1987; Miltner et al. 1995). Because fitness is affected by both size and mortality risk, growth rates may influence ontogenetic niche shifts.

Predation risks for mobile predators and prey have been difficult to quantify (Walters and Juanes 1993). In small lake systems where complex refuge habitat is readily available, small fish are able to retreat to refugia in the presence of predators (Werner et al. 1983). However, large areas of many lakes lack this structure even though habitat boundaries exist. In these systems habitat shifts still occur (e.g., Post and McQueen 1988), but discrete temporal shifts, where individuals assess habitat-specific profitability, may be precluded.

Age-0 Bear Lake sculpin Cottus extensus, a species endemic to Bear Lake in Utah and Idaho, shift habitats ontogenetically, consistent with growth

\footnotetext{
* Corresponding author: jim_ruzycki@nps.gov

${ }^{1}$ Present address: National Park Service, Aquatic Resources Center, Post Office Box 168, Yellowstone National Park, Wyoming 82190, USA.
}

Received March 16, 1998; accepted January 13, 1999 optimization. Sculpin hatch during late spring in the littoral zone, and larvae quickly disperse throughout the epipelagic zone of Bear Lake (Ruzycki et al. 1998). Postsettlement larvae inhabit both the cold profundal and warm littoral zones. Juvenile sculpin located in the profundal zone feed on benthos during the day and undergo a diel vertical migration (DVM) into warmer metalimnetic waters at night, which increases digestion and growth rates (Wurtsbaugh and Neverman 1988; Neverman and Wurtsbaugh 1994). This behavior suggests temperatures in the profundal zone are not optimal for growth. In contrast to the fish in the profundal zone, age- 0 sculpin in the littoral zone feed at night and seek refuge during the day (J. Ruzycki, unpublished data).

Bottom-trawl catches during 1991 and 1992 suggested that juveniles, which initially located in the profundal zone, relocated to the littoral zone during their first summer. The relatively warmer littoral-zone temperatures should be more favorable for growth (Neverman and Wurtsbaugh 1994), and densities of invertebrate prey are higher there than in the colder profundal zone (Wurtsbaugh and Hawkins 1990).

The movement of larval sculpin away from spawning habitat and the habitat switch from the profundal to the littoral zone is also consistent with the distribution of potential predators of these small-bodied juveniles. Adult sculpin are cannibalistic and densities of adults are high in shallow water and rocky substrates of the spawning habitat. During summer, many of these adults move off- 
shore to the profundal-zone habitat, whereas others remain in the littoral-zone habitat. Another predator of age- 0 sculpin are Bonneville whitefish Prosopium spilonotus, and these predators are located primarily below the thermocline throughout the summer. After initial benthic orientation in the profundal zone, migration by juvenile sculpin to the littoral zone may therefore be a response to avoid these predators.

Daily increment patterns of otoliths are known to be controlled by environmental factors (Campana and Neilson 1985; Neilson and Geen 1985; Wright et al. 1991), and changes in contrast have been used to identify the rearing history of fish exposed to different environmental conditions (Zhang et al. 1995). Transition areas of otoliths have also been shown to be associated with changes in ontogeny (Fitzhugh et al. 1997). Further, sub-daily temperature fluctuations have been demonstrated to increase the contrast of daily growth increments of juvenile fish (Campana and Neilson 1985; Neilson and Geen 1985). Juvenile Bear Lake sculpin that inhabit the relatively cold profundal zone undergo a daily vertical migration into the warmer metalimnion at night (Wurtsbaugh and Neverman 1988), potentially inducing daily increments of high contrast. We used the change in contrast of daily increments of wild age- 0 sculpin to confirm their ontogenetic history of habitat residence, their individual size at the time of the habitat shift, and their habitat-specific growth rates.

By examining the distribution of age-0 sculpin during their initial year and by evaluating patterns in their daily otolith increments, we tested the hypothesis that age- 0 juveniles undergo ontogenetic habitat shifts. We also examined underlying mechanisms, and two additional hypotheses were addressed: (1) that habitat shifts were related to habitat-specific growth rates, and (2) that shifts were in response to mortality risk. We concentrated on both growth rate and potential mortality risk because of their direct influence on fitness for sizestructured populations (Werner and Hall 1988).

\section{Methods}

Study site.-Bear Lake, located in northeast Utah and southeast Idaho, is a $282-\mathrm{km}^{2}$, tilt-block lake at an elevation of $1805 \mathrm{~m}$; its maximum depth is $63 \mathrm{~m}$. Most of the bottom sediment is fine marl at depths beyond $23 \mathrm{~m}$ (Smart 1958). Substrate in shallow water is predominated by sand on gradual slopes and gravel, cobble, and boulders on the precipitous eastern shore. Macrophytes are limited,

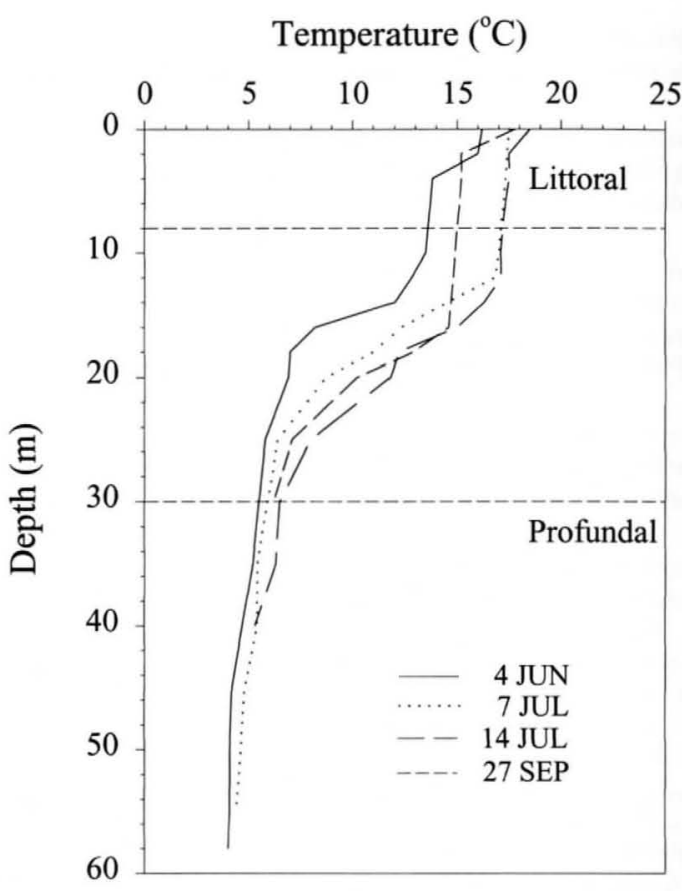

FIGURE 1.-Temperature profiles on four dates during 1992 illustrating the temperature differential between the profundal zone and littoral habitats.

except in the far northern section of the lake. The lake is oligotrophic and typically dimictic, summer surface temperatures reach $19-21^{\circ} \mathrm{C}$ and bottom temperatures remain year-round at $3-5^{\circ} \mathrm{C}$ (Lamarra et al. 1986). Westerly winds predominate during summer, inducing strong currents; seiches up to 4 $\mathrm{m}$ have been measured. Mean annual biomass of benthic invertebrates is very low $\left(0.34 \mathrm{~g} / \mathrm{m}^{2}\right.$ dry weight) compared to other temperate lakes. The benthic invertebrate biomass also declines rapidly between the depths of 15 and $35 \mathrm{~m}$, and the biomass of the taxa consumed by sculpin is $10-12$ times greater in shallow water than in the profundal zone (Smart 1958; Wurtsbaugh and Hawkins 1990).

Habitat demarcation.-For the purposes of this investigation, the lake was divided into two habitat types based on environmental variables expected to influence the growth rate of age-0 sculpin. The two habitat zones were nominally classified: littoral (2-8-m depth) and profundal zone (30-50-m depth). The littoral is located above the thermocline from June through August, whereas the profundal zone is located well below the thermocline during this period (Figure 1). Although age-0 sculpin inhabit the 9-29-m intermediate depths, this 
area was not regularly sampled due to unpredictable temperatures resulting from seiches.

Juvenile distribution.-Beginning 23 May 1992, the onset of free-swimming behavior of larvae was monitored with neuston nets (Ruzycki et al. 1998). The disappearance of larval sculpin from neuston net samples was used as an indication of the onset of benthic residence of juveniles. To determine the spatiotemporal distribution of age- 0 and older sculpin in their benthic habitat, we trawled at 2week intervals from 18 June to 23 September and again on 11 November 1992 with a semiballoon otter trawl (2.9-m headrope, 5.3-mm mesh body, and $1-\mathrm{mm}$ mesh net liner in the cod end). The trawl was pulled at $1 \mathrm{~m} / \mathrm{s}$ for $20 \mathrm{~min}$. Every 2 weeks, we randomly selected 8 profundal zone and 12 littoral sites to trawl (areas of rocky substrates were excluded from this random selection process). Rocky substrates were not sampled, but less than $1 \%$ of the bottom habitat is composed of rocky substrates (Smart 1958; Ruzycki et al. 1998). Profundal-zone sites were trawled during the day because juvenile sculpin vacate the bottom at night (Wurtsbaugh and Neverman 1988). Littoral sites were trawled at night because previous sampling indicated sculpin were most vulnerable then. Juvenile sculpin were measured to the nearest $0.5 \mathrm{~mm}$ standard length (SL), and subsamples were retained for diet and otolith analysis. Additional juveniles were subsampled, blotted dry, and weighed to the nearest $0.1 \mathrm{~g}$ to develop lengthweight relationships.

Distribution and diets of potential predators.Potential predators of age- 0 sculpin in Bear Lake include adult sculpin, large Bonneville whitefish, cutthroat trout Oncorhynchus clarki, and lake trout Salvelinus namaycush. Seasonal habitat-specific density (number/ha) of adult sculpin was estimated from trawl catches by assuming the trawl captured all sculpin in its path (i.e., $100 \%$ efficiency). Trawl area $\left(\mathrm{m}^{2}\right)$ was estimated as the product of the width of the headrope and distanced towed. The areas of the profundal zone $\left(100 \mathrm{~km}^{2}\right)$ and littoral $\left(40 \mathrm{~km}^{2}\right)$ were calculated from a hypsographic curve. Adults were measured (total length; TL) and a subsample was sacrificed for diet analysis. All predators used for diet analysis were immediately placed on ice, and stomachs were preserved in a $10 \%$ formalin solution. Depth distribution of adult sculpin at three depth strata was also sampled throughout the lake during 27-31 July 1992 (littoral; metalimnetic intersect, 11-17 m; and profundal zone). Littoral and metalimnetic depths were sampled at nine locations and the profundal zone was sampled at four locations. At each location and depth stratum, duplicate trawls were pulled for $20 \mathrm{~min}$ at night. For this sampling we used a larger semiballoon otter trawl (4.9-m headrope, 12.7- $\mathrm{mm}$ mesh body, and $3.2-\mathrm{mm}$ mesh net liner in the cod end) than the one used to determine juvenile distribution.

Large Bonneville whitefish ( $>250 \mathrm{~mm}$ TL), cutthroat trout, and lake trout depth distributions were inferred from several gill-net surveys conducted during 1987 (Wurtsbaugh and Hawkins 1990), 1992 (Tolentino and Nielson 1996), and 1993 (authors, unpublished data). Each of these surveys included sampling within the littoral and profundal zone during June, August, and October. Predators captured during these gill-net surveys were subsampled for diet analysis; fish were placed on ice and their stomachs were subsequently dissected and preserved in a $10 \%$ formalin solution.

Otolith analyses.-Habitat-specific growth rates, evidence for habitat shifts, and body size corresponding to the time of the habitat shift were determined from daily growth increments of sagittal otoliths from juvenile sculpin collected in bottom trawls. Dissected otoliths were cleansed in bleach (sodium hypochlorite) to remove adhering tissue, rinsed in deionized water, and stored in $95 \%$ ethanol (Secor et al. 1991). Otoliths were then dried, and each pair was mounted on a glass microscope slide using a thermoplastic polymer (Crystal Bond 509, Aremco Products Inc.). Using a compound light microscope, increments were counted twice on whole otoliths from primordium to edge along a transect free of any secondary primordia (Szedlmayer and Able 1992). The mean increment count was used for all analyses. All otolith radius measurements were made on the anterior segment along the anterior (rostrum) to posterior (postrostrum) axis with a calibrated ocular micrometer at 400 or $1,000 \times$ magnification. The anterior radius was preferred over the posterior because of a high incidence of secondary primordia on the posterior portion of otoliths.

To validate aging of fish from counts of daily increments, we analyzed 9-12 otoliths from fish collected every 2 weeks from July through August 1992. Increment counts were then compared to the interval between the estimated hatching date and sample date. Three independent counts of increments were also made on 96 otoliths by separate observers to verify counts of the primary observer. To validate otolith size as a predictor of fish size, 121 otoliths from fish $9.5-32 \mathrm{~mm}$ SL were measured from primordium to anterior rostral projec- 
tion (Secor et al. 1991) and regressed against fish standard length.

Juvenile sculpin were also reared in the laboratory to verify otolith age measurements. Eggs were collected from the lake on 22 May 1992 and hatched the same day in transport to the laboratory. Fry were placed in a $250-\mathrm{L}$ aquarium and fed an ad libitum diet of live chironomid larvae. After 21 d, 10 fish were sacrificed, and their otoliths were prepared as described above. Increments were counted for each fish, and otoliths were compared to otoliths dissected from day-of-hatch specimens.

A change in the degree of contrast in daily increments of the otoliths was compared from fish collected in the littoral and profundal-zone habitats. An abrupt change from high contrast to low contrast was used to identify a switch from the profundal zone to the littoral habitat. Fish standard length at the time of contrast change was determined by measuring the radius of the otolith at the outermost increment of high contrast.

Habitat-specific daily growth rates were determined from measurements of the daily increment width of otoliths. Because of the correlation between otolith radius and fish body length (see Results), increments produced in the warm littoral were hypothesized to be wider than those produced by fish inhabiting the cold profundal zone. Otoliths were dissected from a subsample of 27 fish that were randomly selected from biweekly bottomtrawl collections (1 July-26 August 1992; size range $12-24.5 \mathrm{~mm} \mathrm{SL}$ ). Widths of the initial 10 increments on either side of the habitat switch mark were measured and compared (Neilson and Geen 1985), and mean daily width of these 10 increments was calculated. Daily increment width was converted to daily growth rate $(\mathrm{mm} / \mathrm{d})$ based on a regression of fish standard length on otolith radius (OR). Growth in length was then converted to growth in mass based on a regression of wet mass on SL.

\section{Results}

\section{Distribution of Age-O Sculpin}

During most of the summer, catches of juvenile sculpin were higher in the littoral than in the profundal zone (Figure 2a). During July and August, catch rates appeared to increase in both zones, littoral catches continuing to exceed those in the profundal zone. By 11 November, however, juvenile catches in the littoral had decreased markedly.

The mean size of juvenile sculpin captured in the littoral was consistently larger than the mean size in the profundal zone. From July through August, size-frequency distributions from the two habitats indicated that juveniles in the littoral were larger than juveniles from the profundal zone (Figure 3 ). In late September, the size-frequency distributions were similar among the two habitats.

\section{Distribution of Potential Predators}

Adult sculpin spawn on shallow, rocky substrates from April through early June (Ruzycki et al. 1998). Density estimates of adult sculpin from bottom trawls were similar in the two habitats from June to September (Figure 2b; Bonferroni multiple $t$ tests; $P>0.05$ ). Beginning in late-September and continuing through mid-November, profundalzone densities exceeded littoral densities (Bonferroni multiple $t$ tests; $P<0.005$ ). During late July, catch rates of adults in the three depth strata were similar (analysis of variance [ANOVA], $F=2.23$, df $=2, P=0.14$ ).

Large Bonneville whitefish, cutthroat trout, and lake trout inhabited all depth strata during the spring before thermal stratification. With the exception of cutthroat trout less than $350 \mathrm{~mm}$ TL, these predators were captured almost exclusively below the thermocline during the summer. After thermal destratification, typically in October, these predators moved into shallow water and were again found throughout a wide range of depth strata.

\section{Diets of Potential Predators}

Only eight juvenile sculpin were observed, one per stomach, in 8 of the 167 adult sculpin sacrificed for diet analysis. This cannibalism occurred from June through September 1992; five of the stomachs were from the littoral and three from the profundal zone. No juvenile sculpin were found in the diets of 59 large Bonneville whitefish captured in our trawls during 1992. During 1993, four juvenile sculpin were found in the diets of 46 Bonneville whitefish captured in gill nets, but none of these were age- 0 individuals. Although sculpin predation has been documented by both cutthroat trout and lake trout, few age- 0 sculpin have been found in their diets (Wurtsbaugh and Hawkins 1990), and no age-0 sculpin were found in the diets of 79 cutthroat trout and 54 lake trout caught in gill nets during 1993.

\section{Otolith Observations and Analyses}

Validation analyses of otoliths indicated that increments were formed daily. A linear regression 


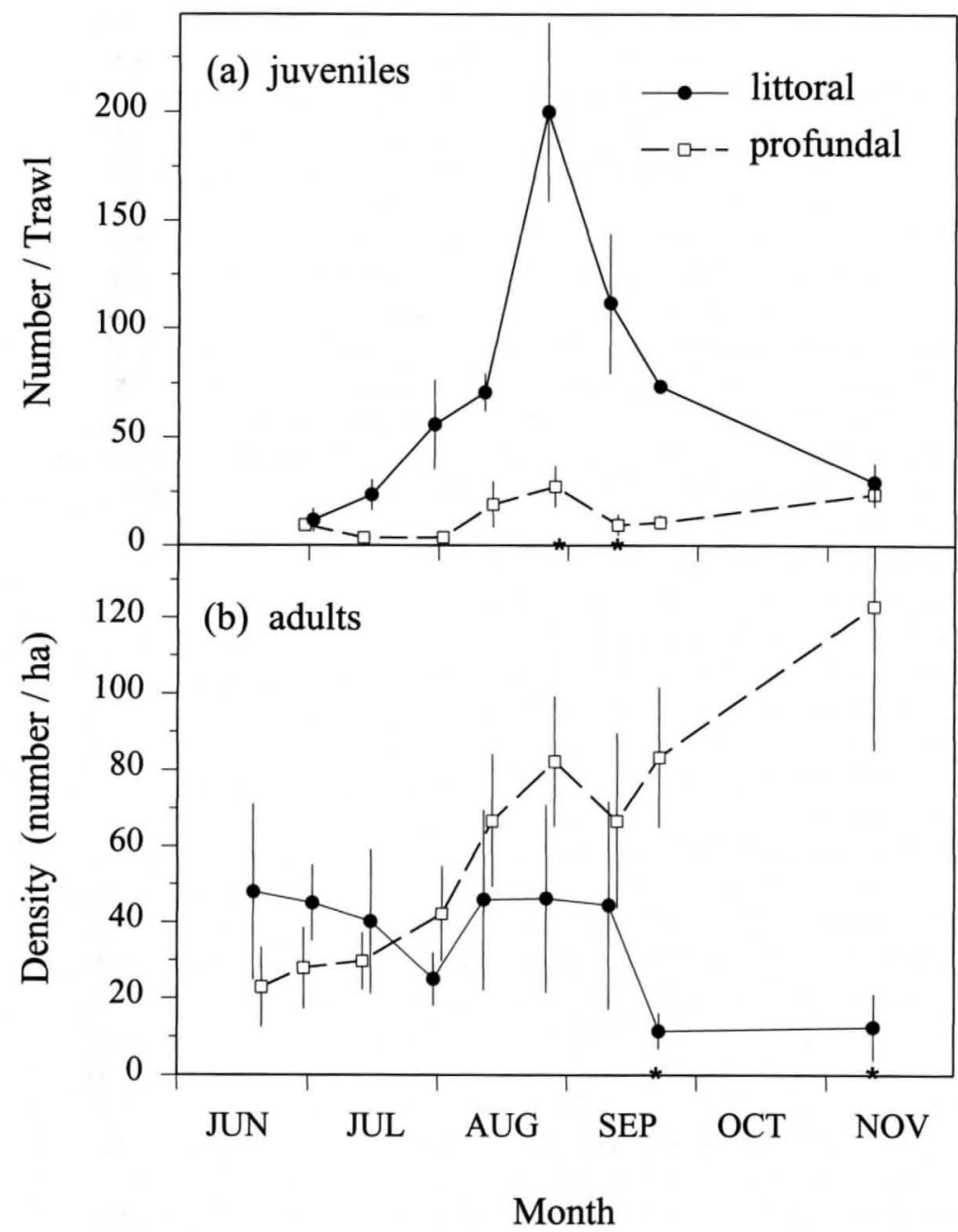

FIGURE 2.-(a) Profundal-zone (30-50 m) and littoral $(2-8 \mathrm{~m})$ trawl catches of juvenile Bear Lake sculpin and (b) profundal-zone and littoral density indices of age-1 and older sculpin, as determined from bottom-trawl catches. For each profundal-zone sample date, $N=8$, except November where $N=6$. For each littoral sample date, $N=$ 12 , except November where $N=8$. Error bars indicate \pm SE. Asterisks on the $x$-axis denote dates when abundance estimates were significantly different between habitats (Bonferroni adjusted $t$-tests: $P<0.0063$ ).

between day of year $(D)$ and increment count (IC) was best described by the relationship

$$
\mathrm{IC}=1.006(D)-148,
$$

for which $N=111, r^{2}=0.99, P<0.001$. The slope of this line (1.006) was not significantly different from 1.0 (analysis of covariance [ANCOVA]: $F=1.28, \mathrm{df}=1, P=0.26$ ), suggesting that increments were formed daily. The $x$-intercept of this line was the 148th day of the year $(\mathrm{SE}=7.4)$, which corresponds to 28 May 1992. This date is not significantly different from our observation of initial sculpin hatching on 23 May 1992 ( $t$ test, df
$=1, P>0.05$ ) nor from peak catch rates of yolk sac larvae in the neuston nets on 29 May $1992(t$ test, $\mathrm{df}=1, P>0.05$ ). Three independent counts of increments on a subset of otoliths indicated no significant difference among reader counts (ANOVA: $F=0.00$, df $=2, P>0.99$ ).

Increment counts of fish raised in the laboratory also validated daily increment formation. Fish sacrificed $21 \mathrm{~d}$ after hatching had a mean increment count of $20.5(\mathrm{SD}=1.05, N=10)$. Although counts were in close agreement with age, increments formed by the laboratory fish were not as distinct as those of wild individuals. 


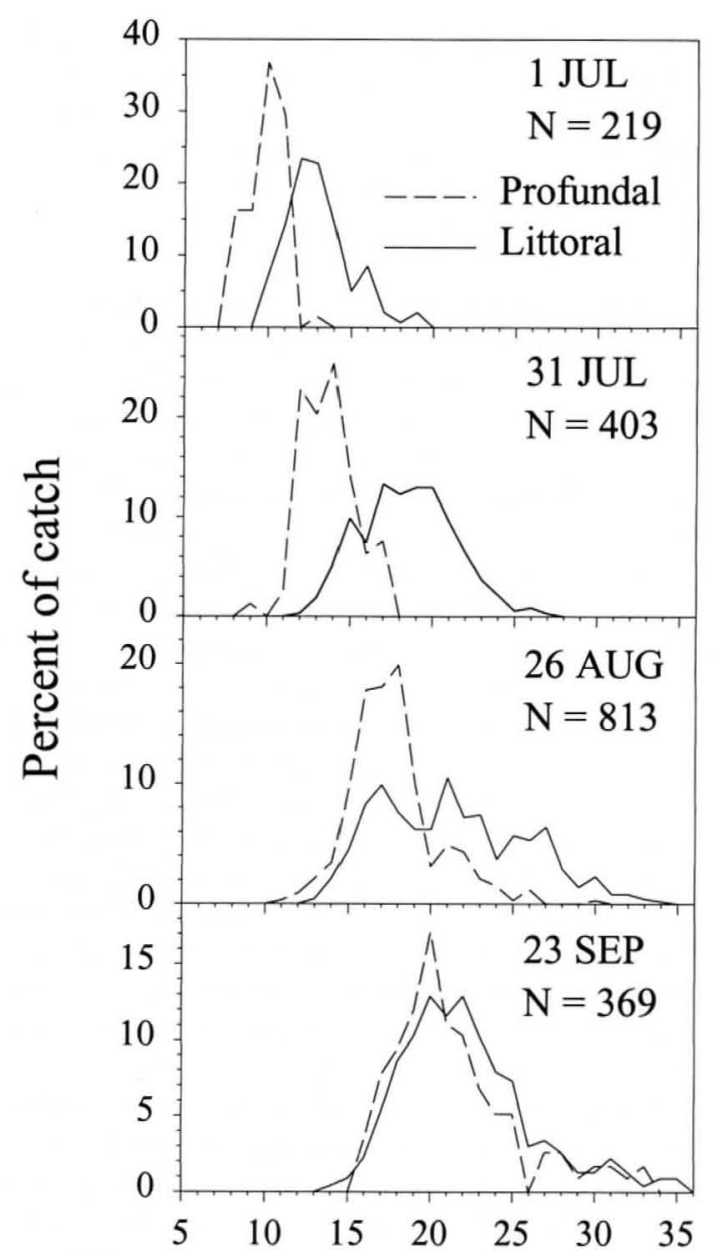

Standard length (mm)

FIGURE 3.-Size-frequency distributions of juvenile sculpin captured with the bottom trawls in the littoral and profundal zone during 1992. The abundances used to estimate the frequency polygons were tabulated at 1$\mathrm{mm}$ intervals. Sample sizes $(N)$ and dates are indicated.

Evidence for habitat switching was recorded in the pattern of daily otolith growth. Juvenile sculpin captured in the profundal zone had greater contrast between daily increments than did the corresponding increments of juveniles captured in the littoral (compare Figure 4a, b). Daily increments of all otoliths of juveniles captured in the profundal zone were easily discernable and showed a high degree of contrast (e.g., Figure 4a). Complete increment counts were possible on $88 \%(N=50)$ of the otoliths from juveniles captured in the profundal zone. Moreover, until September no change in contrast was observed in the growth increments from oto- liths of juveniles captured in the profundal zone. In comparison, complete increment counts were possible on only $77 \%(N=107)$ of the otolith pairs from fish captured in the littoral. Of these, $93 \%$ were of either entirely low contrast $(13 \%)$ or showed a change in the contrast $(80 \%)$ of the increments. Furthermore, all otoliths with a contrast change had high contrast increments beginning near the primordium and lower contrast increments near the outer edge. This evidence also suggests that the high contrast increments were formed in the profundal zone and the switch to the littoral resulted in increments of lower contrast. Widths of daily increments from profundal-zone residents $(3.1 \mu \mathrm{m})$ were significantly narrower $(N=37$; paired $t$-test, $P<0.001)$ than littoral widths $(5.4$ $\mu \mathrm{m})$.

Measurements of otolith radius at the habitat switch mark indicated that juvenile sculpin migrated from the profundal zone to the littoral at a wide range of sizes (range $=8-24 \mathrm{~mm} \mathrm{SL}$, mean $=16.2 \mathrm{~mm}, \mathrm{SD}=4.2, N=169$; Figure 5). Early in the summer, juveniles switched habitats at smaller sizes than they did during August and September. From June through July, most juveniles switching from the profundal zone to the littoral were larger than the average-sized juvenile in the profundal zone (Figure 5).

\section{Juvenile Growth Rate}

Habitat-specific growth rates, as measured from otolith increments, indicated faster growth in the littoral than in the profundal zone. The use of otolith radius (OR; $\mathrm{mm}$ ) as a predictor of fish length $(\mathrm{SL} ; \mathrm{mm})$ was well described by the linear relationship

$$
\mathrm{SL}=4.45+42.01 \mathrm{OR},
$$

for which $N=184$ and $r^{2}=0.96$.

Conversion of standard length to grams wet mass $(m)$ for juveniles was described by the following equation $\left(N=189, r^{2}=0.97\right)$ :

$$
m=\left(1.18 \cdot 10^{-5}\right) \mathrm{SL}^{3.11} \text {. }
$$

By using equations (2) and (3) and measurements of otolith radii and daily increment widths, absolute growth in wet mass $(\mathrm{g} / \mathrm{d})$ in the littoral $\left(G_{\text {lit }}\right)$ and profundal zone $\left(G_{\text {prof }}\right)$ regressed against individual length was best described by the following equations:

$$
G_{\mathrm{lit}}=\left(1.16 \cdot 10^{-6}\right) \mathrm{SL}^{2.88},
$$

for which $N=55$ and $r^{2}=0.93$; and 


$$
G_{\text {prof }}=\left(1.64 \cdot 10^{-6}\right) \mathrm{SL}^{2.51},
$$

for which $N=64$ and $r^{2}=0.97$.

The slopes of these regressions were significantly different (ANCOVA test for homogeneity of slopes: $F=10.0, P<0.01)$, but the intercepts were similar (ANCOVA test for difference in intercepts: $F=1.28, P=0.26$ ). These absolute growth rates equate to average growths in body mass of $2.5 \% / \mathrm{d}$ in the profundal zone and $5 \% / \mathrm{d}$ in the littoral.

\section{Discussion}

During the summer of 1992, age-0 juvenile sculpin that initially resided in the profundal zone switched habitats by migrating to the littoral. Three lines of evidence indicate that age- 0 juvenile sculpin shift habitats through ontogeny: (1) habitat-specific abundances; (2) size-frequency distributions; and (3) changes in the pattern of daily otolith increments. The most conclusive evidence for this summer habitat shift was expressed in otolith microstrucure.

\section{Otolith Observations}

All age-0 Bear Lake sculpin captured in the profundal zone were characterized by narrow, highcontrast daily increment patterns. The DVM of age- 0 sculpin located in the cold profundal zone exposes these individuals to subdaily temperature fluctuations, whereas littoral residents live in an environment with relatively constant temperatures. Therefore, the change in contrast of daily increments of age- 0 sculpin captured in the littoral is consistent with an early history of profundal-zone residence and the associated behavioral temperature fluctuations, coupled with a habitat shift to the more consistent temperatures of the littoral. The change in contrast of otolith increments with movement to the littoral was also accompanied by the corroborating significant increase in the width of daily increments. This increase in width is consistent with an increase in summer growth rate in the warmer littoral.

Ninety-three percent of all age- 0 sculpin captured in the littoral showed either a change in the contrast of their daily increment patterns, indicating a habitat switch, or an entire pattern of wide and low contrast increments, consistent with exclusive use of the littoral. The few juveniles captured in the littoral that showed a daily increment pattern consistent with the profundal zone were probably recent recruits. Furthermore, few age-0 juveniles returned to the profundal zone before
September, as evidenced by the consistent high contrast of daily increments of fish captured there. This suggests that once juvenile sculpin encountered the littoral, they did not return to the less profitable profundal zone before September.

\section{Habitat Shifts}

Comparative size frequency distributions also suggest a habitat shift from the profundal zone to the littoral during July and August. If habitat switching was not occurring, then the modes of the size-frequency polygons would be expected to diverge because of the faster growth rate of fish in the littoral. Recruitment of individuals from the profundal zone to the littoral would decrease the modal shift of the littoral size distribution. In fact, the range of sizes in the littoral increased through September, the smallest individuals changing little in size but the largest increasing nearly two-fold. This large size variation in late summer suggests a variety of growth histories for littoral inhabitants consistent with a mixture of longtime littoral residents and those that recently switched habitats. The nearly identical size distributions in September suggest that individuals from both habitats were intermingling. This time begins a second habitat shift when littoral individuals begin to move offshore.

Juvenile sculpin switched from the profundal zone to the littoral at a wide range of sizes. Results of the examination of the otoliths of sculpin captured in the littoral also suggested that more large than small profundal-zone residents were migrating (Figure 5). We cannot be certain, however, that larger fish emigrated from the profundal zone at a faster rate than did smaller fish. Smaller migrants may experience higher attrition in the littoral due to size-selective predation.

A primary benefit of switching habitats appears to be an increase in growth rate. By moving to the littoral, juveniles moved into a warmer environment with increased prey densities (Wurtsbaugh and Hawkins 1990) and, according to otolith measurements, doubled their growth. Observed movements into the littoral to increase growth rates are consistent with other behavior of age-0 juvenile sculpin. Neverman and Wurtsbaugh (1994) suggested that juvenile sculpin located in the colder profundal zone migrate into the water column at night to the relatively warmer metalimnion to increase digestion rates and consequent growth rates. This diel migration also suggests that temperature, not food, is limiting growth in the profundal zone. Further, by increasing their growth rates, age- 0 

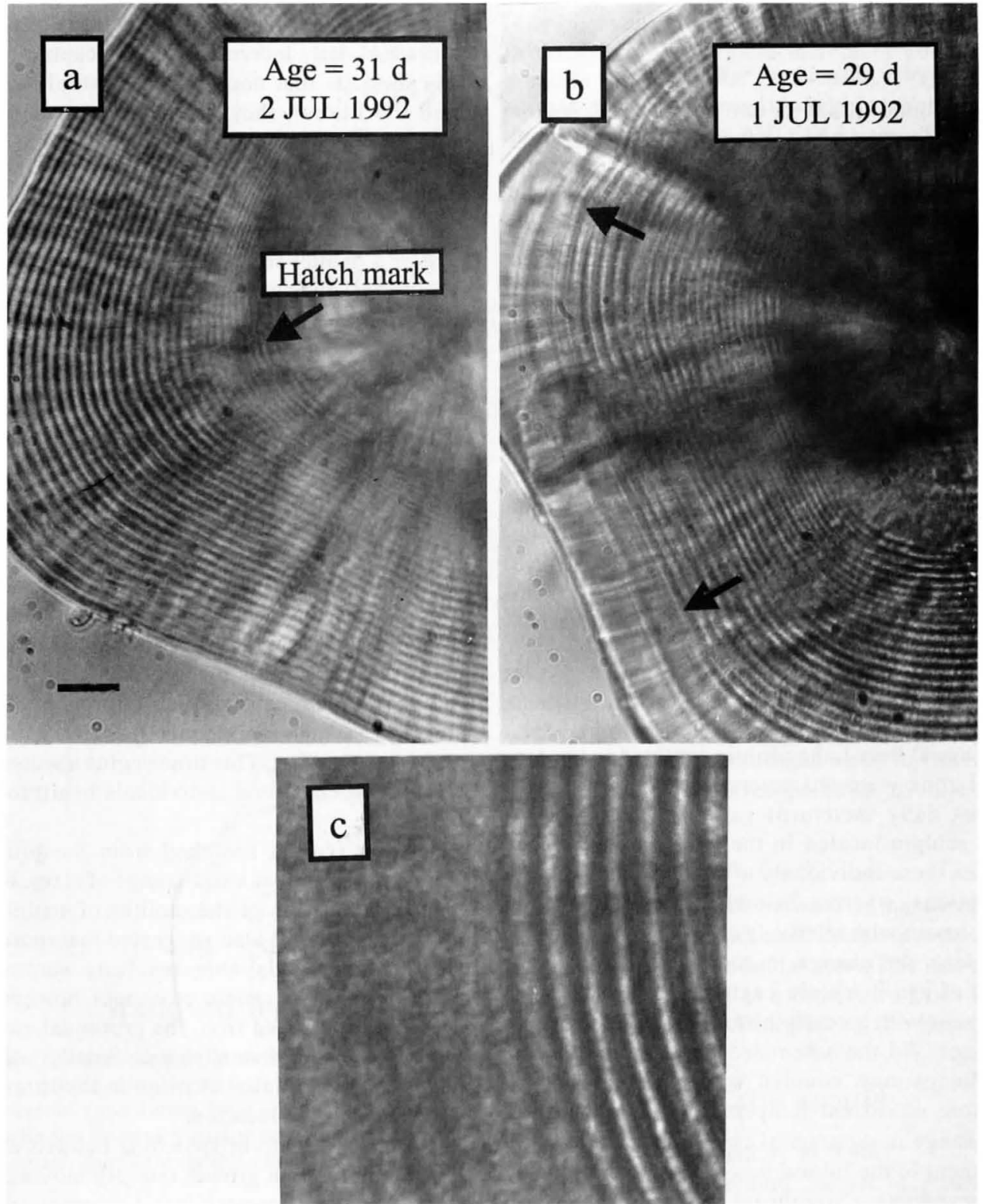

FIGURE 4.-Photomicrographs of sagittal otoliths of Bear Lake sculpin captured in the (a) profundal zone and (b) the littoral zone. Note the high contrast increments of the profundal-zone inhabitant beginning at the arrow and extending to the outer edge. Also note the abrupt change in contrast of the increments of the littoral inhabitant (inferred as a habitat shift from the profundal zone to the littoral), as indicated by the arrows. Age and date of capture of each individual are indicated; bar $=10 \mu \mathrm{m}$. (c) An area of detail of the otolith from the littoral inhabitant is also shown. Although of lower contrast, daily increments of littoral inhabitants are discernable.

juveniles may be increasing their probability of survival by decreasing the time they are vulnerable to predation (Houde 1987; Rice et al. 1987; Miller et al. 1988; Luecke et al. 1990).

Given the apparent benefit of the littoral, why did larvae initially disperse from a warm, food- rich spawning habitat to the profundal zone? This behavior may develop for a variety of reasons and two hypotheses appear plausible. First, larval sculpin may be attempting to disperse from a spawning area densely-populated with large adults (Ruzycki et al. 1998). Second, larval sculpin may not be 


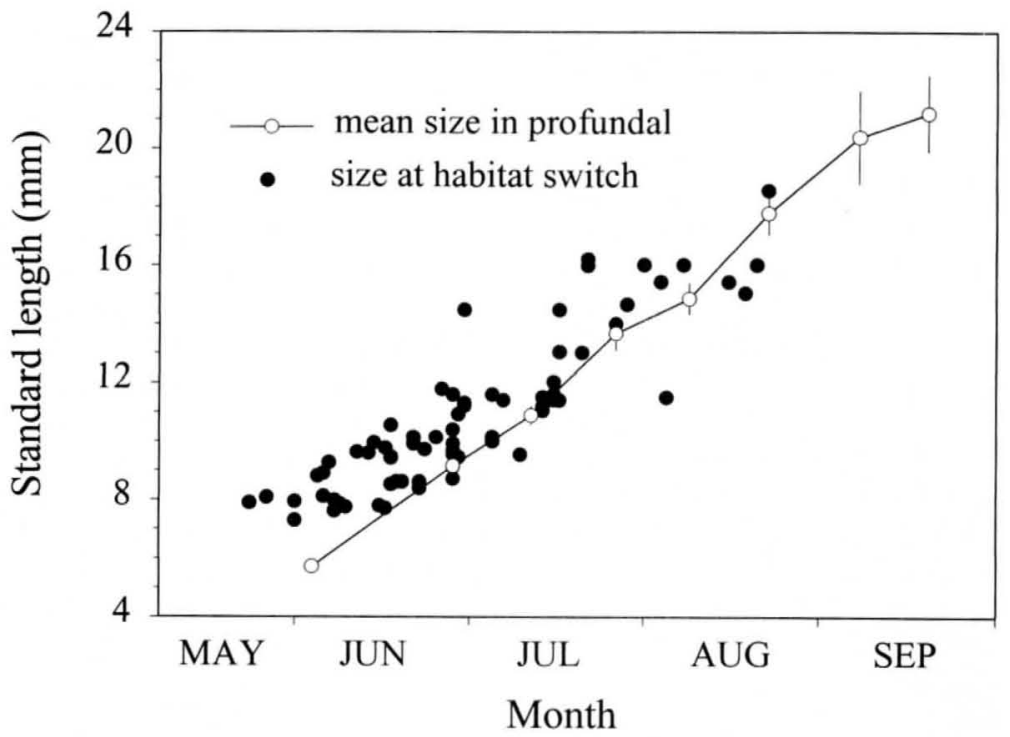

FIGURE 5.-The standard length of juvenile Bear Lake sculpins at the time of their habitat switch, as determined from otoliths. The line depicts the mean size of juveniles $( \pm \mathrm{SE})$ in the profundal zone as determined from bottomtrawl catches.

able to select a specific habitat because of strong currents and their limited swimming ability.

\section{Predation and Mortality Risk}

Few age- 0 sculpin were found in the diets of predators. The only documented predation of age- 0 juveniles was from adult sculpin, and juveniles occurred in less than $5 \%$ of these diets. The lack of age- 0 sculpin predation by the other potential predators suggests that they may not be strongly influencing the distribution of age-0 juveniles. The habitat shift of age- 0 sculpin from the profundal zone to the littoral is, however, consistent with the deepwater distribution of these predators during summer thermal stratification. Small $(<350 \mathrm{~mm}$ TL) cutthroat trout are an exception to this deepwater predator distribution. These fish are located in the littoral during this period. However, during 1993 their diet exceeded $90 \%$ invertebrates during summer months (authors, unpublished data).

If a trade-off between growth rate and predation risk for age-0 sculpin exists in Bear Lake during the summer, then it would necessarily occur in the littoral because this is where growth rates are maximized (Werner and Hall 1988). Adult sculpin were the only documented predators of age- 0 sculpin in the littoral during summer, and this level of predation was probably too low to offset the advantage of the higher littoral growth rates. A mortalityrisk, growth-rate model developed to investigate this trade-off also predicted that all sizes of age0 sculpin should inhabit the more profitable littoral, despite this predation risk from adult sculpin (Ruzycki 1995).

During September and October, prior to thermal destratification, age-0 sculpin began to move offshore away from the littoral. This behavior is also consistent with an avoidance of salmonid predators that move into the littoral after thermal destratification. Cutthroat trout, lake trout, and large Bonneville whitefish are known predators of larger juvenile sculpin. Thermal destratification also reduces the metabolic benefits of littoral temperatures. Consequently, growth rates should be similar among habitats after autumn turnover. However, it is unclear why juveniles would switch habitats prior to destratification. This behavior may be induced by a change in photoperiod or a reduction in benthic food resources in the littoral. As large visual predators enter the littoral and when growth rates for sculpin concomitantly decline, the profundal zone may become the optimal habitat for larger juveniles.

Adult sculpin also migrated to deeper water during late summer and autumn and all size-classes of sculpin inhabit the profundal zone during late autumn and winter periods. This may be a period when age- 0 sculpin are exposed to cannibalism. Laboratory experiments demonstrated that sculpin cannibalism is inversely related to age- 0 body size 
where juveniles less than $15 \mathrm{~mm} \mathrm{SL}$ were three times more vulnerable than those $25 \mathrm{~mm} \mathrm{SL}$ or larger (Ruzycki 1995). Age-0 sculpin that migrated to the littoral during the summer incurred higher growth rates and grew to significantly larger sizes. It is therefore likely, that these migrating juveniles incur lower probabilities of mortality during winter months than those that remain in the profundal zone during their entire first-year growing season.

\section{Habitat Shift Mechanisms}

Although habitat switching behavior was indicated empirically, there was no size threshold at which juvenile sculpin switched habitats, as has been reported for other species that may show facultative responses (Post and McQueen 1988; Werner and Hall 1988). It is unlikely that juvenile sculpin respond facultatively by assessing prey densities or predation pressure. Bear Lake is probably too large for an inefficient swimmer, like juvenile sculpin, to avoid predation by retreating to a refuge habitat. Relatively small, structurally complex systems, such as those inhabited by bluegills Lepomis macrochirus, may enable these juveniles to respond facultatively to an environmental variable (Mittelbach 1986). This idea is supported by Post and McQueen's (1988) observation that horizontal, diel migrations by juvenile yellow perch Perca flavescens did not occur in larger systems where the distances traveled were greater than $200 \mathrm{~m}$. In Bear Lake, a juvenile sculpin that moved from the profundal zone to the littoral would also have to migrate farther than $200 \mathrm{~m}$.

If sculpin are not responding facultatively to prey or predator abundance, then another mechanism of dispersal away from the profundal zone must be responsible for movement to the littoral. Neverman and Wurtsbaugh (1994) suggested that diel vertical migrations by juveniles to the pelagic metalimnion is a thermoregulatory response. This diel vertical migration may also displace profundalzone inhabitants to the warmer littoral, thereby serving a thermoregulatory function at this separate scale. Although not measured, currents within the metalimnion or along the bottom of the epilimnion (Dillon and Powell 1979; Wetzel 1983) may contribute to sculpin dispersal by moving fish from the pelagic zone toward the littoral. If these currents are primarily unidirectional (prevailing winds are west and southwesterly during summer), they could incrementally displace fish migrating into the pelagic metalimnion each night. Diel vertical migrations by juvenile fish in estuaries transport them to favorable habitats (Fortier and Leg- gett 1983; Boehlert and Mundy 1988). Currents and diel vertical migrations are also important in postsettlement recruitment of juvenile fishes in marine environments (Sponaugle and Cowen 1997). Once juvenile sculpin encounter the warmer benthic habitat of the littoral, they may cease vertical migratory behavior. Incremental displacement by currents may also contribute to the higher frequency of larger fish switching habitats (Figure 5) because the larger, presumably older, fish would have spent more nights in this advective, metalimnetic water mass.

If age- 0 sculpin are not responding facultatively to the presence of predators and if the habitat switch from the profundal zone to the littoral is a consequence of a complex set of behaviors associated with diel vertical migration, metalimnetic water mass transport, and thermal selection, then habitat switching behavior may be genetically set. That is, age- 0 sculpin may not be capable of altering their behavior based on relatively short-term annual differences in prey abundance or predation risk (Sih 1987). Densities of adult sculpin were at a 6-year low in 1992 (W. Wurtsbaugh, unpublished data), which probably limited the risk from predation during this sampling period. It is therefore possible that habitat switching behavior developed in the presence of greater predation risk during years when adult sculpin densities and cannibalism were much higher. The low incidence of age- 0 sculpin in the diets of other predators may also have been influenced by the relatively low numbers of age- 0 juveniles during this and similar years.

\section{Conclusions}

Because Bear Lake sculpin are endemic and important forage for both the indigenous and introduced salmonines, the Utah Division of Wildlife Resources and Idaho Department of Fish and Game have emphasized monitoring their annual abundance. Effectively monitoring first-year abundance will provide the first indication of the strength that year's cohort. The suite of diel and seasonal habitat migrations, however, complicates accurate monitoring. The continuous summertime habitat shift dictates sampling both the littoral and profundal zone, and the high within-habitat spatial variability (see Figure 2) requires numerous replicates. The diel vertical migration of age- 0 individuals in the profundal zone dictates daytime trawling there, but daytime trawl avoidance in shallow water requires nighttime trawling. Therefore, knowledge of ontogenetic habitat shifts and 
environmental factors influencing habitat choice is important for accurate monitoring.

This study revealed that the distribution, behavior, and ontogenetic habitat selection of a juvenile fish during the initial 4 months of life may be controlled by a complex set of factors. Juvenile sculpin exhibited three ontogenetic habitat shifts during their initial year: (1) migrating away from their hatching site, (2) migrating from the profundal zone to the littoral during summer months, and (3) returning to the profundal zone during late summer and autumn. By migrating to the warm, food-rich littoral, age-0 sculpin incurred significantly greater growth rates, thereby increasing their potential fitness through increases in body size. We collected no evidence that predation was a major controlling factor. We believe the observed wide range of sizes at which sculpin migrate from the profundal and littoral zones are a function of the spatial scale of this system, the swimming ability of juveniles, and a lack of facultative responses. Further understanding of sculpin habitat selection through ontogeny will require a more thorough investigation of the manner in which individual fish migrate between habitats and the flexibility of habitat choice.

\section{Acknowledgments}

We thank P. Chase, C. Housely, C. Lay, R. Orme, and N. Bouwes for help with field and laboratory work. C.P. Hawkins, F.J. Messina, D.A. Beauchamp, C. Kraft, and two anonymous reviewers provided valuable comments on earlier versions of this manuscript. We also thank B. Nielson and S. Tolentino for providing unpublished data. This research was funded by Federal Aid in Sport Fish Restoration (project F-47-R, study 5) administered through the Utah Cooperative Fish and Wildlife Research Unit and the Utah Division of Wildlife Resources.

\section{References}

Boehlert, G. W., and B. C. Mundy. 1988. Roles of behavioral and physical factors in larval and juvenile fish recruitment to estuarine nursery areas. Pages 51-67 in M. P. Weinstein, editor. Fish and shellfish transport through inlets. American Fisheries Society, Symposium 3, Bethesda, Maryland.

Campana, S. E., and J. D. Neilson. 1985. Microstrucure of fish otoliths. Canadian Journal of Fisheries and Aquatic Sciences 42:1014-1032.

Crowder, L. B., M. E. McDonald, and J. A. Rice. 1987. Understanding recruitment of Lake Michigan fishes: the importance of size-based interactions between fish and zooplankton. Canadian Journal of Fisheries and Aquatic Sciences 44:141-147.
Dillon, T. M., and T. M. Powell. 1979. Observations of a surface mixed layer. Deep-Sea Research 26A:915932.

Fitzhugh, G. R., S. W. Nixon, D. W. Ahrenholz, and J. A. Rice. 1997. Temperature effects on otolith microstrucure and birth month estimation from otolith increment patterns in Atlantic menhaden. Transactions of the American Fisheries Society 126:579593.

Fortier, L., and W. C. Leggett. 1983. Vertical migrations and transport of larval fish in a partially mixed estuary. Canadian Journal of Fisheries and Aquatic Sciences 40:1543-1555.

Houde, E. D. 1987. Fish early life dynamics and recruitment variability. Pages 17-29 in R. D. Hoyt, editor. 10th annual larval fish conference. American Fisheries Society, Symposium 2, Bethesda, Maryland.

Lamarra, V., C. Liff, and J. Carter. 1986. Hydrology of Bear Lake basin and its impact on the trophic state of Bear Lake, Utah/Idaho. Great Basin Naturalist 46:690-705.

Luecke, C., J. A. Rice, L. B. Crowder, S. E. Yeo, and F. P. Binkowski. 1990. Recruitment mechanisms of bloater in Lake Michigan: an analysis of the predatory gauntlet. Canadian Journal of Fisheries and Aquatic Sciences 47:524-532.

Miller, T. J., L. B. Crowder, J. A. Rice, and E. A. Marshall. 1988. Larval size and recruitment mechanisms in fishes: toward a conceptual framework. Canadian Journal of Fisheries and Aquatic Sciences 45:1657-1670.

Miltner, R. J., S. W. Ross, and M. H. Posey. 1995. Influence of food and predation on the depth distribution of juvenile spot Leiostomus xanthurus in tidal nurseries. Canadian Journal of Fisheries and Aquatic Sciences 52:971-982.

Mittelbach, G. G. 1981. Foraging efficiency and body size: a study of optimal diet and habitat use by bluegills. Ecology 62:1370-1386.

Mittelbach, G. G. 1986. Predator-mediated habitat use: some consequences for species interactions. Environmental Biology of Fishes 16:159-169.

Neilson, J. D., and G. H. Geen. 1985. Effects of feeding regimes and diel temperature cycles on otolith increment formation in juvenile chinook salmon $\mathrm{On}$ corhynchus tshawytscha. Fishery Bulletin 83:91101.

Neverman, D., and W. A. Wurtsbaugh. 1994. The function of diel vertical migration for a juvenile fish Cottus extensus. Oecologia 98:247-256.

Post, J. R., and D. J. McQueen. 1988. Ontogenetic changes in the distribution of larval and juvenile yellow perch Perca flavescens: a response to prey or predators? Canadian Journal of Fisheries and Aquatic Sciences 45:1820-1826.

Post, J. R., and A. Prankevicius. 1987. Size-selective mortality in young-of-the-year yellow perch Perca flavescens: evidence from otolith microstrucure. Canadian Journal of Fisheries and Aquatic Sciences 44:1840-1847.

Rice, J. A., L. B. Crowder, and F. P. Binkowski. 1987. 
Evaluating potential sources of mortality for larval bloater Coregonus hoyi: starvation and vulnerability to predation. Canadian Journal of Fisheries and Aquatic Sciences 44:467-472.

Ruzycki, J. R. 1995. Ontogenetic habitat shift of Juvenile Bear Lake sculpin Cottus extensus. Master's thesis. Utah State University, Logan.

Ruzycki, J. R., W. A. Wurtsbaugh, and C. Lay. 1998. Reproductive ecology and early life history of a lacustrine sculpin, Cottus extensus (Teleostei, Cottidae). Environmental Biology of Fishes 53:117127.

Secor, D. H., J. M. Dean, and E. H. Laban. 1991. Manual for otolith removal and preparation for microstructural examination. University of South Carolina, Belle W. Baruch Institute for Marine Biology and Coastal Research, Technical Publication 1991-01, Columbia.

Sih, A. 1987. Predators and prey lifestyles: an evolutionary and ecological overview. Pages 203-224 in W. C. Kerfoot and A. Sih, editors. Predation: direct and indirect impacts on aquatic communities. New England University Press, Hanover, New Hampshire.

Smart, E. W. 1958. An ecological study of the bottom fauna of Bear Lake Idaho and Utah. Doctoral dissertation. Utah State University, Logan.

Sponaugle, S., and R. K. Cowen. 1997. Early life history traits and recruitment patterns of Caribbean wrasses (Lambridae). Ecological Monographs 67:177-202.

Szedlmayer, S. T., and K. W. Able. 1992. Validation studies of daily increment formation for larval and juvenile summer flounder Paralichthys dentatus. Canadian Journal of Fisheries and Aquatic Sciences 49:1856-1862.

Tolentino, S., and B. Nielson. 1996. Bear Lake cutthroat trout enhancement program. Utah Division of Wild- life Resources, Federal Aid in Sport Fish Restoration, F-26-R-6, Five Year Completion Report, Salt Lake City.

Walters, C. J., and F. Juanes. 1993. Recruitment limitation as a consequence of natural selection for use of restricted feeding habitats and predation risk taking by juvenile fishes. Canadian Journal of Fisheries and Aquatic Sciences 50:2058-2070.

Werner, E. E., and J. F. Gilliam. 1984. The ontogenetic niche and species interactions in size-structured populations. Annual Review of Ecology and Systematics 15:393-425.

Werner, E. E., J. F. Gilliam, D. J. Hall, and G. G. Mittelbach. 1983. An experimental test of the effects of predation risk on habitat use in fish. Ecology 64 : 1540-1548.

Werner, E. E., and D. J. Hall. 1988. Ontogenetic habitat shifts in bluegill: the foraging-rate predation risk trade-off. Ecology 69:1352-1366.

Wetzel, R. G. 1983. Limnology. Saunders College Publishing, New York.

Wright, P. J., D. Rowe, and J. E. Thorpe. 1991. Daily growth increments in the otoliths of Atlantic salmon parr Salmo salar and the influence of environmental factors on their periodicity. Journal of Fish Biology 39:103-113.

Wurtsbaugh, W. A., and C. P. Hawkins. 1990. Trophic interactions between fish and invertebrates in Bear Lake, Utah-Idaho. Utah State University, Special Publication of the Ecology Center, Logan.

Wurtsbaugh, W. A., and D. Neverman. 1988. Post-feeding thermotaxis and daily vertical migration in a larval fish. Nature (London) 333:846-848.

Zhang, Z., R. J. Beamish, and B. E. Riddell. 1995. Differences in otolith microstrucure between hatcheryreared and wild chinook salmon Oncorhychus tshawytscha. Canadian Journal of Fisheries and Aquatic Sciences 52:344-352. 